\title{
Adsorption of Phenol from Water on Natural Minerals
}

\author{
Alicja Puszkarewicz ${ }^{1 *}$, Jadwiga Kaleta', Dorota Papciak \\ 1 Rzeszow University of Technology, The Faculty of Civil and Environmental Engineering and Architecture, \\ Department of Water Purification and Protection, Poznańska 2, 35-084 Rzeszów, Poland \\ * Corresponding author's e-mail: apuszkar@prz.edu.pl
}

\begin{abstract}
Phenol and its derivatives (chlorophenol, nitrophenol, methylphenol, cresol etc.) belong to highly toxic contaminants, and their occurrence in industrial and municipal sewage as well as in groundwater carries a high threat to the environment and human health. Elimination of such contaminants is one of the major challenges in solving the global environmental problems. Implementation of pro-ecological methods of water treatment is associated with the use of natural, cheap and unprocessed materials, with the possibility of their repeated use. The article presents the results of the studies on the use of powdery adsorbents for the removal of phenol from aqueous solutions. The following natural minerals were used: attapulgite - Abso'net Superior Special (ASS) and alganite - Abso'net Multisorb (AM). Tests were performed under non-flowing conditions, in series, depending on the type and dose of adsorbents. Tests were conducted on a model solution of phenol with the initial concentration of $\mathrm{C}_{0}=20 \mathrm{mg} / \mathrm{dm}^{3}$, at the temp. of $20^{\circ} \mathrm{C}$. Alganite mineral (AM) proved to be effective in adsorption of phenol. Maximum adsorption capacity $\mathrm{P}=0.21 \mathrm{~g} / \mathrm{g}$, was obtained for a dose $10 \mathrm{mg} / \mathrm{dm}^{3}$. Almost complete removal of phenol (99.9\%) was obtained for a dose of $500 \mathrm{mg} / \mathrm{dm}^{3}$. For natural attapulgite - Abso'net Superior Special (ASS) the maximum adsorption capacity (at a dose $5 \mathrm{mg} / \mathrm{dm}^{3}$ ) amounted to $\mathrm{P}=0.15 \mathrm{~g} / \mathrm{g}$. The efficiency of phenol removal at the level $99 \%$ was obtained at a dose of $1000 \mathrm{mg} / \mathrm{dm}^{3}$ ).
\end{abstract}

Keywords: phenol, adsorption, attapulgite, alganite

\section{INTRODUCTION}

The presence of phenol in the aquatic environment may cause a decrease in the quality of water, as well as lead to the death of aquatic organisms. Almost all phenols are toxic, and some of them are carcinogenic to humans. If its concentration exceeds the value of $5.6 \mathrm{~g} / \mathrm{m}^{3}$, it disrupts the water self-purification processes. In contrast, at the concentrations above $30 \mathrm{~g} / \mathrm{m}^{3}$, it completely inhibited photosynthesis [Al-Khalid et al. 2012, Bazrafshan et al. 2013].

The presence of phenols in ecosystems is associated with the production and degradation of many pesticides, as well as the production of industrial and municipal sewage. Large quantities (up to several $\mathrm{g} / \mathrm{m}^{3}$ ) are found in wastewater from various industries, mainly coking plants, gas plants, plastic mills, synthetic fibres, gasification plants for solid fuels, processing of crude oil, production of dyes, plant protection chemicals, and pharmaceutical plants. Phenols are also found in the wastewater from other industrial plants in which phenol is used as a raw material [Ahmaruzzaman 2007, Michałowicz et al. 2007].

Phenol is biodegradable in an aqueous environment; however, only when it is absent in the concentrations toxic to microorganisms [Indu Nair et. al. 2008]. Therefore, it is necessary to develop effective and time-saving methods for removing phenols from wastewater. Photocatalytic oxidation can be used to remove phenols from aqueous solutions and adsorption [Alam et al. 2014, Bielecka-Daszkiewicz 2008]. Various materials such as activated carbon, natural minerals, synthetic polymers and waste materials are used as absorbents [Dąbrowski et al. 2005]. Research was also carried out to assess the effectiveness of cheaper adsorbents, such as peat, fly ash, bentonite and other materials for which high phenol removal efficiency was obtained. An additional advantage of adsorption is the ability to burn and reuse the adsorbent 
[Bizerea Spiridon et al. 2013, Kaleta 2005, Puszkarewicz 2010, Viraraghavan et al. 1998].

This article focuses on determining the effectiveness of phenol removal using natural adsorbents: attapulgite - Abso'net Superior Special (ASS) and alganite - Abso'net Multisorb (AM).

\section{MATERIALS AND METHODS}

\section{Materials}

The subject of the research was a model aqueous solution of phenol $\left(\mathrm{C}_{6} \mathrm{H}_{5} \mathrm{OH}\right)$. It was prepared on the basis of distilled water, to which phenol compounds were added. The initial concentration of phenol in water was $\mathrm{C}_{0}=20 \mathrm{mg} / \mathrm{dm}^{3}$.

In laboratory tests, dusty fractions of the following raw materials were used as adsorbents:

- mineral Abso'Net Superior Special (ASS),

- mineral Abso'net Multisorb (AM),

Characteristics of Abso'Net Superior Special (ASS) adsorption material - catholytic card - Horpol:

- bulk density - $500 \mathrm{~g} / \mathrm{dm}^{3}$

- produced from finely ground mineral called attapulgite, during the activation process at high temperature,

- it is a natural product (it does not contain any chemical additives, it is not modified),

- it is not harmful to people and animals,

- it is resistant to abrasion when subjected to mechanical action,

- after absorbing the fluid it does not decompose,

- has NIH approval.

Attapulgite is a filbrillar silicate with the chemical formula of $\mathrm{Mg}_{5}[\mathrm{Al}] \mathrm{Si}_{8} \mathrm{O}_{20}\left(\mathrm{OH}_{2}\right)_{4}$, showing a relatively large sorption capacity oscillating in the range of $0.15-0.30 \mathrm{mval} / \mathrm{g}$. Like zeolites, it is characterized by features of molecular sieve [Rybiński et. al. 2013].

Characteristics of the Abso'net Multisorb adsorp-tion material (AM) - catholytic card - Horpol:

- made of finely ground mineral called Alganite,

- bulk density $-500 \mathrm{~g} / \mathrm{dm}^{3}$

- it is resistant to abrasion when subjected to mechanical action,

- after absorbing the fluid it does not decompose,

- designed to remove all types of leaks, from industrial fluids, aqueous suspensions, through hydrocarbons (oil, gasoline, oils), organic solvents, to alkaline compounds;

- has NIH approval.

Alganite is made of oiled mineral slates after their deoiling in the process (extraction), resulting in a porous, absorbent, reticular fabric material. It is one of the few materials the production of which is ecological and does not increase the emission of carbon dioxide. During production, more energy is gained than it consumes.

Alganite is a hydrophobic product, resistant to bacterial colonization according to the catalogue card [MKM Holdings LTD group 2014].

\section{Method of conducting research}

The adsorption process was carried out using an adsorbent dried at $105^{\circ} \mathrm{C}$. The phenol content was determined indirectly by indicating the organic carbon content with the GE Analytical Instruments TEST Sievers InnovOx laboratory analyser. The tests were carried out under static (non-flow) conditions. They were made in series depending on the dose of the dusty adsorbent.

Laboratory tests were carried out in two stages:

Stage I -tests to determine the initial conditions for the adsorption process - the effect of $\mathrm{pH}$ and process kinetics

Stage II - determination of the effect of the adsorbent dose on the effectiveness of adsorption and determination of Freundlich adsorption isotherms.

\section{Effect of $\mathrm{pH}$ on the adsorption process}

The tests were performed for $\mathrm{pH}: 2,3,4,5,6$, $7,8,9,10,11,12,13$ And involved adding 12.5 $\mathrm{mg}$ of adsorbent to $250 \mathrm{ml}$ adsorptive, shaking for $0.5 \mathrm{~h}$ and after sedimentation (24h), the phenol in solutionwas determined.

Effect of contact time on the adsorption process under static conditions (adsorption kinetics)

The effect of the contact time on the adsorption process was determined at a sorbent dose of $50 \mathrm{mg} / \mathrm{dm}^{3}$. The initial concentration of phenol in the water tested was $\mathrm{C}_{0}=20 \mathrm{mg} / \mathrm{dm}^{3}, \mathrm{pH}=7$. Five adsorbent weights were poured into five conical flasks, containing $250 \mathrm{~cm}^{3}$ each. Then, each flask was shaken successively for $0.5 ; 1.0 ; 1.5 ; 2.0 ; 2.5$; $3.0 ; 3,5 ; 4.0,4.5,5.0$, hours and left for 24 hours of sedimentation. After this time, the samples were filtered and phenol determinations were made. 
Adsorption of phenol (adsorption capacity) was determined from the equation:

$$
q_{r}=\frac{V \times\left(C_{0}-C\right)}{m}(\mathrm{~g} / \mathrm{g})
$$

where: $V$ - volume of adsorptive $\left(\mathrm{dm}^{3}\right)$

$C_{0}$ and $C$ - initial and equilibrium (final) concentration of phenol $\left(\mathrm{g} / \mathrm{m}^{3}\right)$, $m$ - mass of adsorbent $(\mathrm{g})$

\section{Effect of adsorbent dose on adsorption efficiency}

Effect of adsorbent dose on adsorption efficiency of phenol was conducted at $\mathrm{pH}=7$, contact time $3.5 \mathrm{~h}$, for the doses of AM and ASS from $1-1000 \mathrm{mg} / \mathrm{dm}^{3}$.

\section{Adsorption isotherms}

The separation of the adsorbate between the solution and the adsorbent at steady state was described by Freundlich adsorption isotherms, which represent the relationship between the amount of adsorbed substance and the equilibrium concentration.

In exponential form, the equation has the following form:

$$
y / m=K \cdot C^{1 / n}
$$

where: $y / m$-adsorption capacity,

$K$ - constant isotherm,

$n$ - constant isotherm,

$C$ - equilibrium concentration

The tests were carried out in vessels with the content of $0.5 \mathrm{dm}^{3}$ of adsorption, for the concentration of phenol $\mathrm{C}_{0}=20 \mathrm{mg} / \mathrm{dm}^{3}$, at $\mathrm{pH} 7$ and for variable doses of tested adsorbents from
$1-1000 \mathrm{mg} / \mathrm{dm}^{3}$. The content of the adsorb at steady state $\mathrm{q}_{\mathrm{r}}$, after 3.5 hours of shaking and 24 hours of sedimentation for the tested carbons, was calculated with formula (1).

\section{RESULTS AND DISCUSSION}

\section{Effect of $\mathrm{pH}$}

The effect of the $\mathrm{pH}$ of the solution on phenol adsorption is shown in Figure 1. The phenol particles showed much greater affinity for the adsorbents at a $\mathrm{pH}$ in the range of $1-4$, with the phenol adsorption efficiency for AM being higher than for ASS and fluctuating in the range of $14-16 \%$. This can be explained by the fact that the $\mathrm{pH}$ of the solution may affect the adsorption process also due to the change in the surface properties of the adsorbent. For many solids, the potential-forming ions are $\mathrm{H}+$ and $\mathrm{OH}$ - ions, from which it follows that the surface potential can be influenced by changing the $\mathrm{pH}$ of the solution in which the given solid is located, and the adsorption proceeds with greater intensity when the surface charge of the adsorbent and potential the electric adsorbate are opposite. In the case of very strong adsorption of potential-forming ions on the surface of a solid (which may have occurred in the tests carried out), it may happen that the charge of the adsorption layer changes its sign. Therefore, depending on the $\mathrm{pH}$ of the solution in which the adsorbent is located, it will take up a positive or negative electric charge of the surface [Janusz 2000]. Very low removal of phenol for the AM and ASS (1-3\%) at high $\mathrm{pH}$ could be the result of competition between the $\mathrm{OH}^{-}$ions and dissociated phenol anions [Liu et. al. 2010]. The effectiveness of phenol adsorption for AM was higher than for ASS and fluctuated in the range of $14-16 \%$.

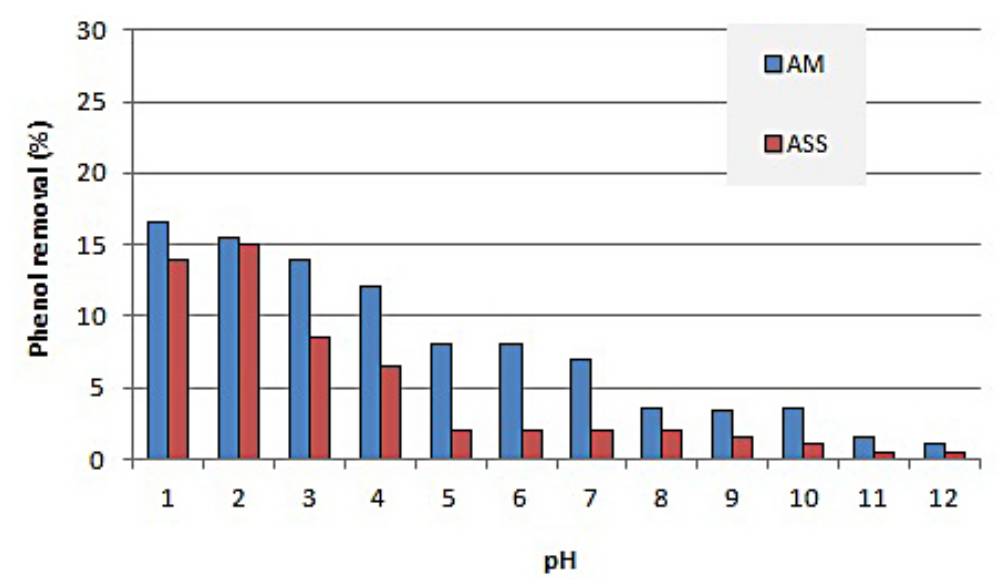

Fig. 1. Effect of $\mathrm{pH}$ on the adsorption of phenol 
For the AM tested, the increase in the adsorption efficiency at the acid reaction was not significant enough to introduce a correction of water $\mathrm{pH}$ and despite visible differences for ASS, further tests were carried out at $\mathrm{pH}=7$.

\section{Adsorption kinetics}

The process of phenol absorption consists of several stages. The first stage is the transport of the adsorbed particle from the solution's bulk phase to the adsorbent boundary layer, followed by external diffusion (on the adsorbent surface), internal diffusion in the adsorbent structure and the last stage involves the reactions from the adsorbate to the active site. The reaction in the active sites is the fastest, but the adsorption kinetics limit the slowest processes. Under static (non-flow) conditions, these phenomena are diffusion at the interface and inside the pores of the adsorbent. Solutions diluted at the adsorption rate are affected by the mixing and shaking time. The concentration of phenol close to the adsorption equilibrium (adopted as equilibrium) for ASS and AM was obtained after 3.5 hours. The effectiveness of adsorption expressed as $\mathrm{C} / \mathrm{C}_{0}$ is illustrated in Figure 2.

In order to describe the adsorption kinetics, two kinetic models are used most often: the pseudofirst-order (PFO) model defined by the Lagergren equation and the secondary model - pseudo-second-order (PSO) popularized by Ho et al. [1999]. The modelling process comes down to matching the empirical results with these equations and choosing the one that better correlates the data. Choosing the right model will not explain the mechanisms controlling the adsorption rate in the system, but it can be helpful in determining the factors limiting the process speed [Płaziński et al. 2011].
The PFO equation, in a differential form, has the following form:

$$
\frac{d q(t)}{d t}=k_{1}\left(q_{e}-q(t)\right)
$$

where: $t$ is the time,

$q$ the amount of adsorbate bound by the adsorbent (this amount may depend on time),

$q_{e}$ corresponds to the value of $q$ in equilibrium, i.e. $q(t \rightarrow \infty)=q_{e}$; $k_{1}$ is a constant, called the PFO constant.

During data analysis, the line form is more commonly used:

$$
\ln \left(q_{e}-q(t)\right)=\ln q_{e}-k_{1} t
$$

The kinetic curves for the adsorbents tested, made in function $\mathrm{f}(\mathrm{t})=\log (\mathrm{qe}-\mathrm{q}(\mathrm{t}))$ are shown in Figure 3. On the basis of simple equations determined with the least squares method, the values of $k_{1}(1 / h)$ speed constants and adsorption capacities in equilibrium were calculated and are given in Table 1.

The pseudo-second order equation (PSO) in a differential form is as follows:

$$
\frac{d q(t)}{d t}=k_{2}\left(q_{e}-q(t)\right)^{2}
$$

where: $k_{2}$ is a constant.

In order to correlate experimental data, the linear representation using which the constant $k_{2}$ and $q_{e}$ are most often relevant is:

$$
\frac{t}{q(t)}=\frac{1}{k_{2} q_{e}^{2}}+\frac{t}{q}
$$

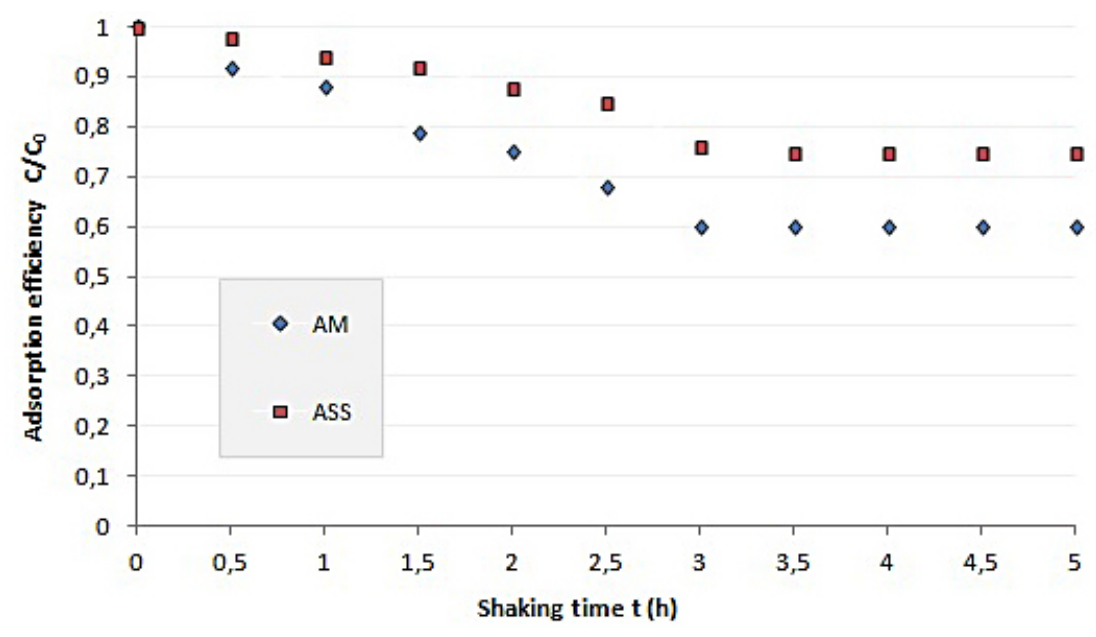

Fig. 2. Influence of adsorption time on the effectiveness of the removal of phenol 
The graphs for PSO were prepared in the function $\mathrm{f}(\mathrm{t})=\mathrm{t} / \mathrm{q}(\mathrm{t})$ and are shown in Figure 4 . Rate constants $k_{2}(g / g \cdot h)$ were calculated from the inclination and displacement coefficients of straight lines. All calculated $\mathrm{k}_{2}$ rate constants and adsorption capacities are shown in Table 1.

With regard to AM and ASS adsorbents, the adsorption kinetics were approximately in line with the PFO model, because the determination coefficients were 0.885 and 0.881 , respectively. We can say that the model is weaker to match the experimental values, which is also indicated by large discrepancies (between calculated and obtained in tests) in the adsorption capacity (several times). Quicker adsorption was performed for AM and the slowest for ASS, as evidenced by $\mathrm{k}_{1}$ rate constants of 1.540 and $0.720 \mathrm{l} / \mathrm{h}$, respectively.

The presented dependences show that the adsorption efficiency increased along with the contact time of the water with the adsorbent, but its speed (the highest in the first 30 minutes) dropped sharply after 3 hours. The adsorption process was much slower and its continuation did not significantly affect the phenol removal efficiency. In further studies (adsorption isotherms and dose effect), due to slight changes in the adsorption kinetics, 3.5 hours was assumed as the mixing time for all adsorbents.

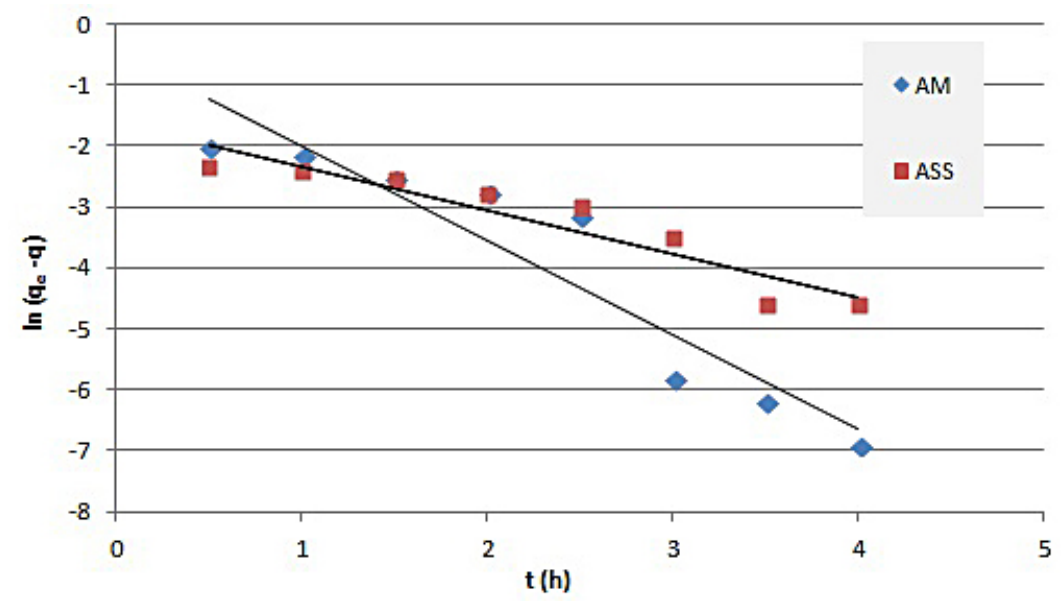

Fig. 3. The course of adsorption kinetics of phenol described pseudo first-order equation

Table 1. Rate constants for PFO and PSO of phenol adsorption on AM and ASS

\begin{tabular}{|c|c|c|c|c|c|c|c|}
\hline \multirow{2}{*}{ Adsorbent } & \multirow{2}{*}{$\mathrm{q}_{\mathrm{r}}(\mathrm{g} / \mathrm{g})$} & \multicolumn{3}{|c|}{ Pseudo-first-order (PFO) } & \multicolumn{3}{c|}{ Pseudo-second-order (PSO) } \\
\cline { 3 - 8 } & & $\mathrm{k}_{1}\left(\mathrm{~h}^{-1}\right)$ & $\mathrm{q}_{\mathrm{e}}(\mathrm{g} / \mathrm{g})$ & $\mathrm{R}^{2}$ & $\mathrm{k}_{2}(\mathrm{~g} / \mathrm{g} \cdot \mathrm{h})$ & $\mathrm{q}_{\mathrm{e}}(\mathrm{g} / \mathrm{g})$ & $\mathrm{R}^{2}$ \\
\hline AM & 0.163 & 1.540 & 0.199 & 0.885 & 0.192 & 0.37 & 0.800 \\
\hline ASS & 0.105 & 0.720 & 0.619 & 0.881 & 772 & 4.21 & 0.005 \\
\hline
\end{tabular}

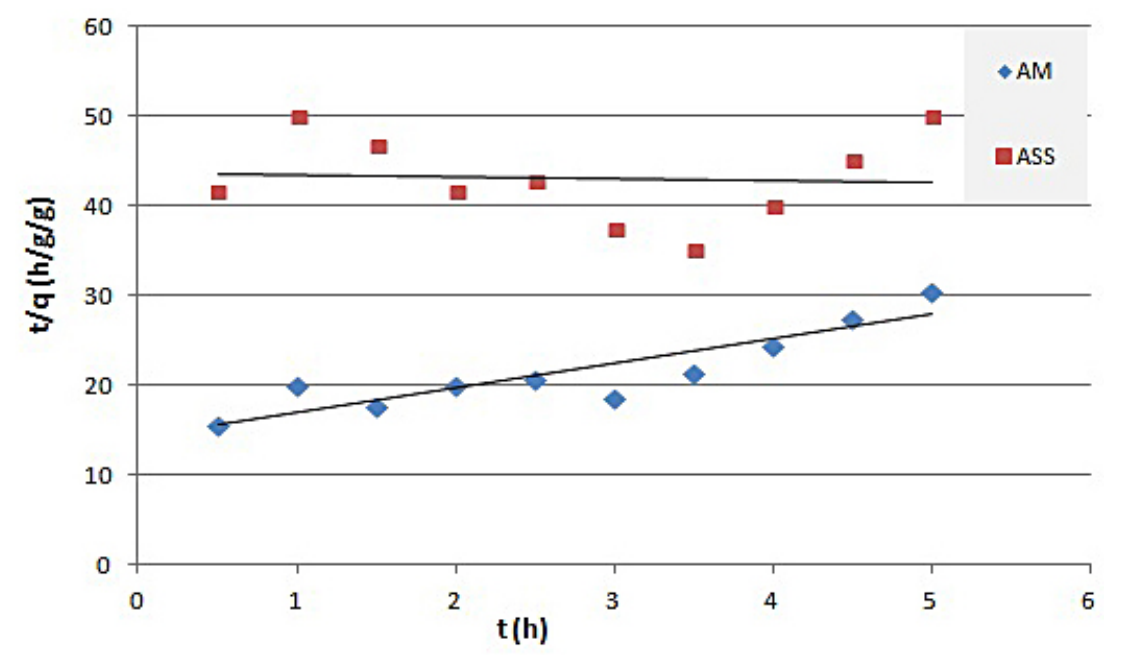

Fig. 4. The course of adsorption kinetics of phenol described pseudo second-order equation 


\section{Adsorption isotherms}

The phenol adsorption isotherms for the adsorbents tested are shown in Figure 5. The determined values of $\mathrm{K}$ in constants, together with the values of the determination coefficients $\mathrm{R}^{2}$ are presented in Table 2. The course of isotherms (determined under static conditions) indicates that the maximum adsorptive capacity for AM (at a dose of 10 $\mathrm{mg} / \mathrm{dm}^{3}$ ) was $\mathrm{q}_{\mathrm{r}}=0.21 \mathrm{~g} / \mathrm{g}$. For ASS, the maximum adsorption capacity was much lower and amounted to $\mathrm{q}_{\mathrm{r}}=0.15 \mathrm{~g} / \mathrm{g}$ (at a dose of $\left.5 \mathrm{mg} / \mathrm{dm}^{3}\right)$. The $\mathrm{K}$ values expressing the maximum adsorption on the adsorbent surface are 0.0862 , and 0.0321 for AM and ASS respectively.

The highest value of the correlation coefficient observed for AM (0.9427) indicates a good adjustment of the theoretical model to the experimental isotherm. Slightly smaller fitting (but still good) of experimental data to the model was demonstrated by ASS (0.9214). The $\mathrm{n}$-factor for the adsorbents tested is greater than 1 , which may mean that the
Table 2. Values of constants $\mathrm{n}$ and $\mathrm{K}$ of Freudlich isotherms

\begin{tabular}{|c|c|c|c|}
\hline \multirow{2}{*}{ Adsorbent } & \multicolumn{2}{|c|}{ Constants of isotherms } & \multirow{2}{*}{$\begin{array}{c}\text { Factor of } \\
\text { determination } \\
R^{2}\end{array}$} \\
\hline & $n$ & $\mathrm{~K}$ & \\
\hline AM & 3.77 & 0.0862 & 0.9427 \\
\hline ASS & 2.16 & 0.0321 & 0.9214 \\
\hline
\end{tabular}

surface concentration of the adsorbate increases more slowly than its concentration in the solution. In principle, no full saturation is achieved, because there are always places with high adsorption energy on the surface. In the analyzed adsorbents, the lowest factor $\mathrm{n}$ is for ASS, which may indicate the possibility of reaching a higher saturation state with the adsorbate than in the case of AM.

\section{Effect of dose on adsorption}

The phenol adsorption efficiency also depended on the amount of adsorbent used. Figure 6

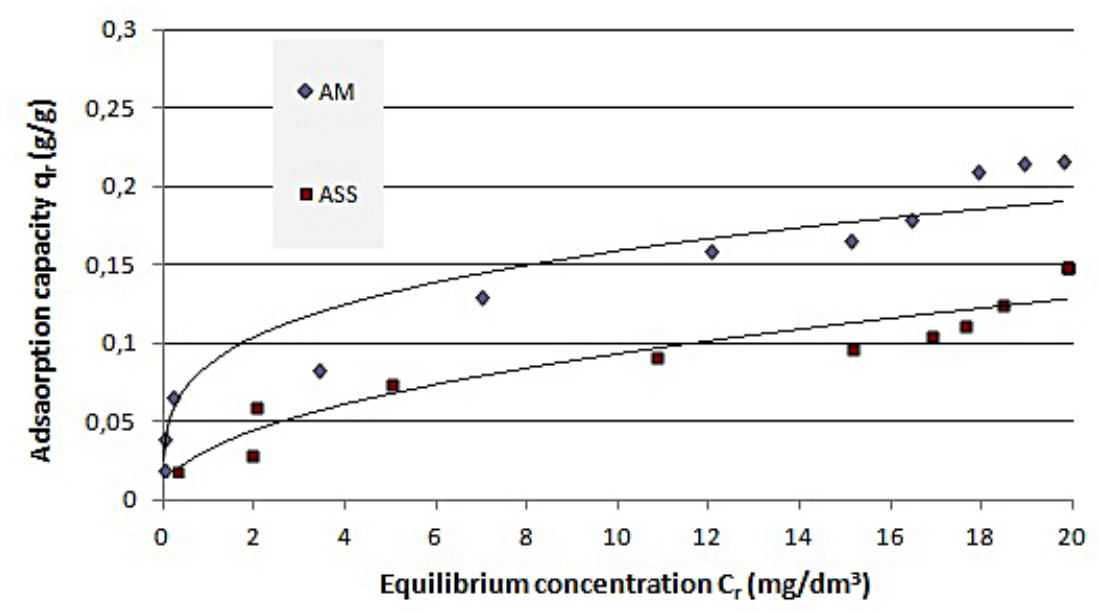

Fig. 5. Adsorption isotherms of phenol onto adsorbent (AM, ASS), temp. $20^{\circ} \mathrm{C}$

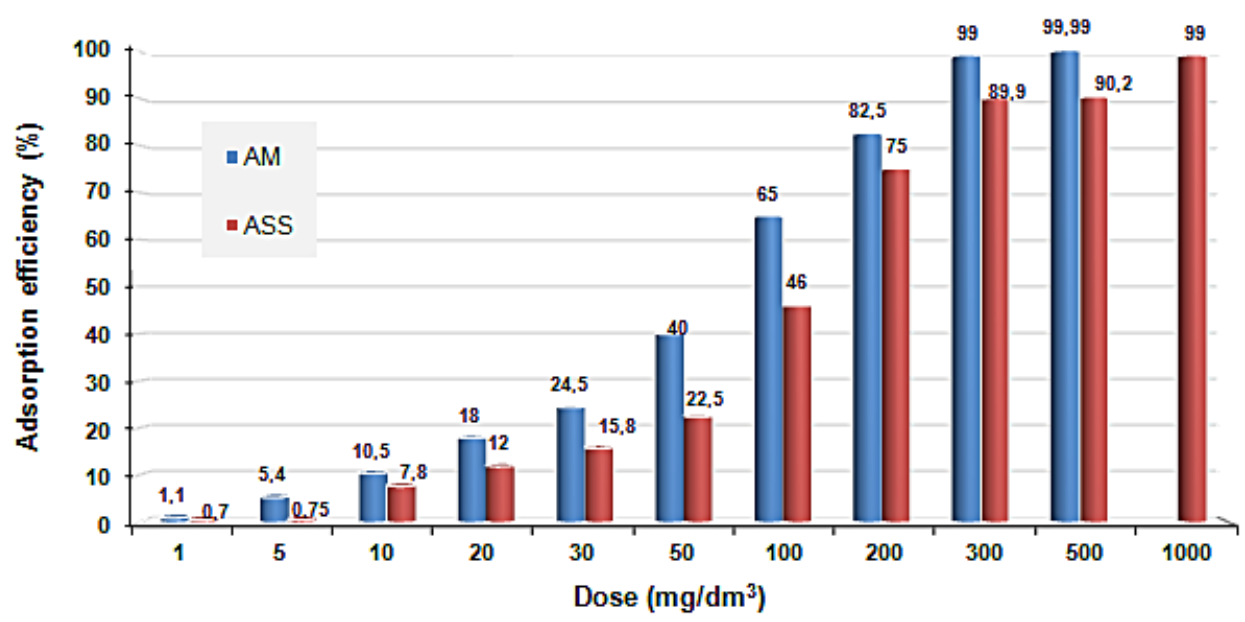

Fig. 6. Effect of dose on the effectiveness of the removal of phenol 
depicts the effect of the adsorbent dose on the percent removal of phenol from the solution. It is clearly seen that the higher dose of adsorbent gave better final efficiency of the process. The efficiency of phenol removal for ASS at the dose of $1000 \mathrm{mg} / \mathrm{dm}^{3}$ was $99 \%$, yielding the equilibrium concentration $\mathrm{C}_{\mathrm{r}}=0.28 \mathrm{mg} / \mathrm{dm}^{3}$. For $\mathrm{AM}$ at a dose of $500 \mathrm{mg} / \mathrm{dm}^{3}$, the equilibrium concentration of phenol was $\mathrm{C}_{\mathrm{r}}=0.02 \mathrm{mg} / \mathrm{dm}^{3}$, which gave 99.9\% adsorption efficiency.

\section{CONCLUSIONS}

1. The $\mathrm{pH}$ of the solution affected the adsorptive capacity of the adsorbents tested. The phenol particles showed much greater affinity for the adsorbents at a $\mathrm{pH}$ in the range of $1-4$, with the phenol adsorption efficiency for AM being higher than for ASS.

2. The adsorption rate changed as a function of the contact time (mixing) of the adsorbents with the adsorbate and dropped sharply after 3 hours. With respect to the adsorbents AM and ASS, the adsorption kinetics proceeded according to the PFO (Pseudo-first-order) model, and the determination coefficients were 0.885 and 0.881 , respectively.

3. Adsorption of phenol for all tested adsorbents was well-described with the Freudlich model. The highest value of the correlation coefficient was obtained for AM (0.9427).

4. Analysis pertaining to the effect of the adsorbents dose showed that the adsorption efficiency in phenol removal clearly increased along with the dose of the adsorbent. For AM at a dose of $500 \mathrm{mg} / \mathrm{dm}^{3}, 99.9 \%$ efficiency was obtained.

5. In the light of the conducted research, the mineral adsorbent $\mathrm{AM}$ effectively removed phenol from water, which enables to use it in water treatment systems. Studies have shown that a natural adsorbent - Abso'net Multisorb (AM), with granulation $<0.1 \mathrm{~mm}$, could be an alternative to activated carbons for effective pre-treatment of phenol-containing solutions.

\section{REFERENCES}

1. Ahmaruzzaman M. 2008. Adsorption of phenolic compounds on low-cost adsorbents: A review, Advances in Colloid and Interface Science (143), 48-67.

2. Alalm M. G. Tawfik A. 2014. Solar photocatalytic degradation of phenol in aqueous solutions using ti- tanium dioxide, International Journal of Chemical, Materials Science and Engineering 8(2), 43-46.

3. Al-Khalid T., El-Naas M. H. 2012. Aerobic Biodegradation of Phenols: A Comprehensive Review, Critical Reviews in Environmental Science and Technology 42, 1631-1690.

4. Bazrafshan E., Mostafapour F. K., Mansourian H. J. 2013. Phenolic Compounds: Health Effects and Its Removal From Aqueous Environments by Low Cost Adsorbents, Health Scope. 2(2), 65-66.

5. Bielicka-Daszkiewicz K. 2008. Removing phenol from wastewaters by oxidation, Przemysł Chemiczny 87(1), 24-32.

6. Bizerea Spiridon O., Preda E., Botez A., Pitulice L. 2013. Phenol removal from wastewater by adsorption on zeolitic composite, Environ Sci. Pollut. Res. 20, 6367-6381.

7. Dąbrowski A., Podkościelny P., Hubicki Z., Barczak Z., Robens E. 2005. Adsorption of phenols on activated carbon, Wiadomości Chemiczne, 59(7-8), 631-694.

8. Ho Y.S., McKay G. 1999. Pseudo-second-order model for sorption processes, Process Biochemistry $34,451-465$.

9. Indu Nair C., Jayachandran K., Shashidhar S. 2008. Biodegradation of phenol, African Journal of Biotechnology 7(25), 4951-4958.

10. Janusz W. 2000. The electrical double layer parameters for the group 4 metal oxide/electrolyte system, Adsorpt. Sci. Technol.18 (2), 117-134.

11. Kaleta J. 2005. Phenols in water medium, Ecology and Technique 73(1), 3-11.

12. Liu Q-S., Zheng T., Wang P., Jiang J.P., Li N. 2010. Adsorption isotherm, kinetic and mechanism studies of some substituted phenols on activated carbon fibers, Chemical Engineering Journal 157, (2-3), 348-356.

13. Michałowicz J., Duda W. 2007. Phenols - Sources and Toxicity, Polish J. of Environ. Stud. 16(3), 347-362.

14. MKM Holdings Ltd Group, 2014. Catalog card.

15. Płaziński W., Rudziński W. 2011. Adsorption kinetics at solid/solution interfaces. The meaning of the pseudo -first - and pseudo -second -order equations, Journal of Polish Chemical Society 65, 11-12, 1055-1067.

16. Puszkarewicz A., 2010. Analysis of phenol adsorption on raw and modified carpathian diatomite, Chemistry-Didactics-Ecology-Metrology 15(2), 189-192.

17. Rybiński, P., Janowska G. 2013. Flammability and other properties of elastomeric materials and nanomaterials. Part II. Nanocomposites of elastomers with attapulgite, nanosilica, nanofibres and carbon nanotubes, Polimery 7-8, 533-542.

18. Viraraghavan T., Alfaro F. M. 1998. Adsorption of phenol from wastewater by peat, fly ash and bentonite, Journal of Hazardous Materials 57, 59-70. 